AJSS, Vol. 8, No. 1, January - June 2009, pp. 9-17

ISSN 0975-3311

https:/ / doi.org/ 10. 12725 / ajss .14.2

\title{
TRENDS AND PATTERN OF URBANIZATION IN INDIA: AN INTER STATE ANALYSIS
}

\section{T. Chandrasekarayya* \& P. Ganesh**}

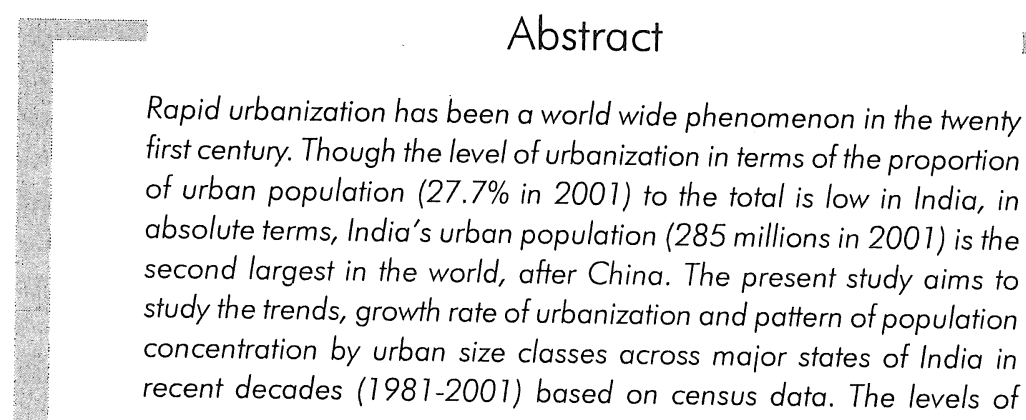

* Department of Population Studies \& Social work, Sri Venkateswara University, Tirupati, India517502, Phone: 09440078579,Email: tcsdps.svu@gmail.com

** Academy of Gandhian Studies, Tirupati, India-517502. Phone: 09052275448, Email: ganeshbhavana@yahoo.com ganeshbhavana2006@ rediffmail.com 
urbanization were high in industrially as well as economically developed states. The pace of urban population has high in backward states. An over whelming proportion of urban population inhabited in class 1 cities.

\section{Introduction}

Rapid urbanization has been a world wide phenomenon in the twenty first century. In developing countries like India, challenge of urbanization becomes even more serious in the context of over population and its consequences. Urbanization in demographic sense, is an increase in the proportion of the Urban population (U) to the Total population (T) over a period of time (Ashish Bose, 1978:3). While in sociological sense, urbanization refers to the phenomenal growth of towns and cities or urban centres (Shankar Rao, 2007:339). Further, urbanization is involving a change from agricultural to non-agricultural occupation and being associated with organizational and behavioural change (Patil, 1993:44).

Though the level of urbanization in terms of the proportion of urban population (27.7\% in 2001) to the total is low in India, in absolute terms, India's urban population (285 million in 2001) is the second largest in world, after China. Further, it is estimated to increase in the range of 435-485 millions by the year 2010 and represent about 41.0 per cent of the total population (Jacob, 2007:71). Moreover, the unique features of India's urbanization are being differentials in the levels as well as pattern of urbanization across the states and diversity in the share of urban population in urban size classes among the states over a period of time. The study of India's urbanization, therefore, assumes added importance. In India, attempts have been made from time to time to study the urbanization at national level in different contents (Ashish Bose, 1978; Patil, 1993; Premi, 2003; and Bhende and Kanitkar, 2006). Inter state analysis on trends and patterns of urbanization are rather rare. In the present context such analysis is highly relevant to a country like India.

\section{Importance}

Proper understanding of the trends, spatial structure and concentration of urban population among the states, especially in recent decades are an essential prerequisite for urban governance as well as other programmes for the development and management of urban areas. In this direction, an attempt is made in the present paper to analyse the trends and patterns of urbanization among major states of India. 


\section{Objectives}

- To study the trends and growth rate urbanization across major states in recent decades (i.e. 1971-2001).

- To examine the pattern of population concentration by urban size classes across major states in recent decades (1981-2001).

\section{Data and Method}

The study is based on the data, collected from Census of India. The analysis is made for the period 1971-2001 taking into account of the latest census years, where in the momentum of urban population growth was found to be increasing. However, the present study covers seventeen major states, which constitute huge share of urban population. The rest of states and union territories are smaller in terms of urban population as well as in area, which is difficult for comparison. The data relating to 1971-81 periods for Assam are not available. Hence, analysis is made on the basis of available information using percentages and ratios.

\section{Results and Discussion}

\section{V.I. Urbanization Across States}

Trends as well as pattern of urbanization across the major states of India are furnished in Table-l. The levels of urbanization were high in Maharastra, Tamil Nadu, Gujarat, Karnataka, Punjab and West Bengal and moved above the level of national average. These states are mostly either economically or industrially developed with higher per capita income, consisting with high concentration of economic activities. Further, a moderate trend of urbanization recorded in states like Andhra Pradesh, Madhya Pradesh, Uttar Pradesh, Haryana, Kerala and Rajasthan. In these states, however the pattern of urbanization is more or less equal to national average. This is due to predominance of agricultural sector and disparities of industrialization in these states. While, backward and hilly states like Bihar, Orissa, Assam, Arunachal Pradesh and Himachal Pradesh had low levels of urbanization, because of socioeconomic backwardness and these states are far behind in industrialization. Further, in these states levels of urbanization is below the national average. 
Table-I : Trends of Urbanisation Across Major States

\begin{tabular}{|c|c|c|c|c|c|}
\hline S.No. & States & 1971 & 1981 & 1991 & 2001 \\
\hline 1. & Andhra Pradesh & 19.31 & 23.25 & 26.84 & 27.08 \\
\hline 2. & Arunachalpradesh & 03.70 & 6.32 & 12.21 & 20.41 \\
\hline 3. & Assam & - & 9.88 & 11.08 & 12.72 \\
\hline 4. & Bihar & 10.00 & 12.46 & 13.17 & 10.47 \\
\hline 5. & Gujarat & 28.08 & 31.08 & 34.40 & 37.75 \\
\hline 6. & Haryana & 17.66 & 21.96 & 24.79 & 29.00 \\
\hline 7. & Himachal Pradesh & 06.99 & 7.72 & 08.70 & 09.79 \\
\hline 8. & Karnataka & 24.31 & 28.91 & 30.91 & 33.98 \\
\hline 9. & Kerala & 16.24 & 18.78 & 26.44 & 25.97 \\
\hline 10. & Madhya Pradesh & 16.29 & 20.31 & 23.21 & 26.67 \\
\hline 11. & Maharastra & 31.17 & 35.03 & 38.73 & 42.40 \\
\hline 12. & Orissa & 08.41 & 11.82 & 13.43 & 14.97 \\
\hline 13. & Punjab & 23.73 & 27.72 & 29.72 & 33.95 \\
\hline 14. & Rajasthan & 17.13 & 20.93 & 22.88 & 23.38 \\
\hline 15. & Tamil Nadu & 30.26 & 32.98 & 34.20 & 43.86 \\
\hline 16. & Uttar Pradesh & 14.02 & 18.01 & 19.89 & 20.78 \\
\hline 17. & West Bengal & 24.75 & 26.49 & 27.39 & 28.03 \\
\hline & All India & 20.22 & 23.73 & 25.72 & 27.78 \\
\hline
\end{tabular}

Source: Registrar General and Census Commissioner, Computed from Census of India, 1981, 1991 and 2001, paper-2, Rural-Urban Distribution. 


\section{V.II. Growth of Urban Population}

The analysis of growth of urban population across major states indicates the trends as well as pattern of urbanization over a period of time (Table-II). The trends in the growth of urban population are characterized by dualism. The pace of growth has generally been high in relatively backward states like Assam, Bihar, Uttar Pradesh, Rajasthan, Orissa, Himachal Pradesh and Madhya Pradesh. This can be attributed government policies popularly known as "a gap-filling approach", where in urban development programmes has been adopted and due to rural-urban migration. It owing to lack of diversification in the agrarian economy, which shows enormity of the situation. However, few developed states like Maharastra, Gujarat, Punjab and Haryana also recorded a high or medium growth. These states attracted population to urban areas due to concentration of economic activities as a result of industrialization, advanced agrarian economy and infrastructural investment.

\section{V.III. Urbanization Across Size Classes}

The analysis of urbanization across size classes of major states reveal that the trends as well as pattern of structural changes in urban population. Indian census classified urban areas into six size classes. However, the smaller towns with population below 20,000 clubbed into one category here for analysis the growth given in Table-III. The proportion population. Data relates to these aspects were given in Table-III. The proportion of population in class I cities has been increasing regional pattern. An overwhelming propoliffer among the major states and reveal a class I cities in West Bengal, Maharastra, Tamil Nadu, Gujaraulation inhabited in in most of the study period. Further, in states like Hara Gujarat and Andhra Pradesh Kerala a moderate (nearly 50-70 per cent) proportion, inhabited Karnataka and the case of National average. In these states, agriculture is pred class I cities, as from slow rate of industrialization. Evidence indicates that abo is predominance apart in the urban population of larger cities was due that about two-thirds of increase (Singh, 1992) and rest as the result of inflow due to a result of natural growth these Class I cities in India are economically prosp (Oberai, 1993). Most of Moreover, the rapid growth can be attributed prosperous with industrialization. manufacturing employment, infrastructural facilit to increased opportunities of (Sivarama Krishnan, et al., 2006:62).

The share of urban population in medium towns (Class II and III) however, have remained constant in most of the states over a period. However, in hilly states like Arunachal Pradesh and Himachal Pradesh, an overwhelming proportion of urban 
Table-II: Annual Exponential Growth Rate of Urbanization Across Major States

\begin{tabular}{|c|c|c|c|c|}
\hline S.No. & States & $1971-81$ & $1981-91$ & 1991-2001 \\
\hline 1. & Andhra Pradesh & 3.94 & 3.55 & 1.37 \\
\hline 2. & Arunachalpradesh & 8.32 & 9.28 & 7.00 \\
\hline 3. & Assam & - & 3.27 & 3.09 \\
\hline 4. & Bihar & 4.34 & 2.65 & 2.57 \\
\hline 5. & Gujarat & 3.42 & 2.90 & 2.80 \\
\hline 6. & Haryana & 4.65 & 3.58 & 4.11 \\
\hline 7. & Himachal Pradesh & 3.02 & 3.11 & 2.81 \\
\hline 8. & Karnataka & 4.08 & 2.55 & 2.53 \\
\hline 9. & Kerala & 3.19 & 4.76 & 0.74 \\
\hline 10. & Madhya Pradesh & 4.45 & 3.71 & 2.71 \\
\hline 11. & Maharastra & 3.35 & 3.27 & 2.95 \\
\hline 12. & Orissa & 5.21 & 3.08 & 2.61 \\
\hline 13. & Punjab & 3.62 & 2.55 & 3.19 \\
\hline 14. & Rajasthan & 4.52 & 3.31 & 2.71 \\
\hline 15. & Tamil Nadu & 2.45 & 1.76 & 3.56 \\
\hline 16. & Uttar Pradesh & 4.78 & 3.29 & 2.84 \\
\hline 17. & West Bengal & 2.75 & 2.54 & 1.84 \\
\hline & All India & 3.79 & 3.09 & 2.73 \\
\hline
\end{tabular}

Source: Registrar General and Census Commissioner, Computed from Census of India, 1981, 1991 and 2001, paper-2, Rural-Urban Distribution. 


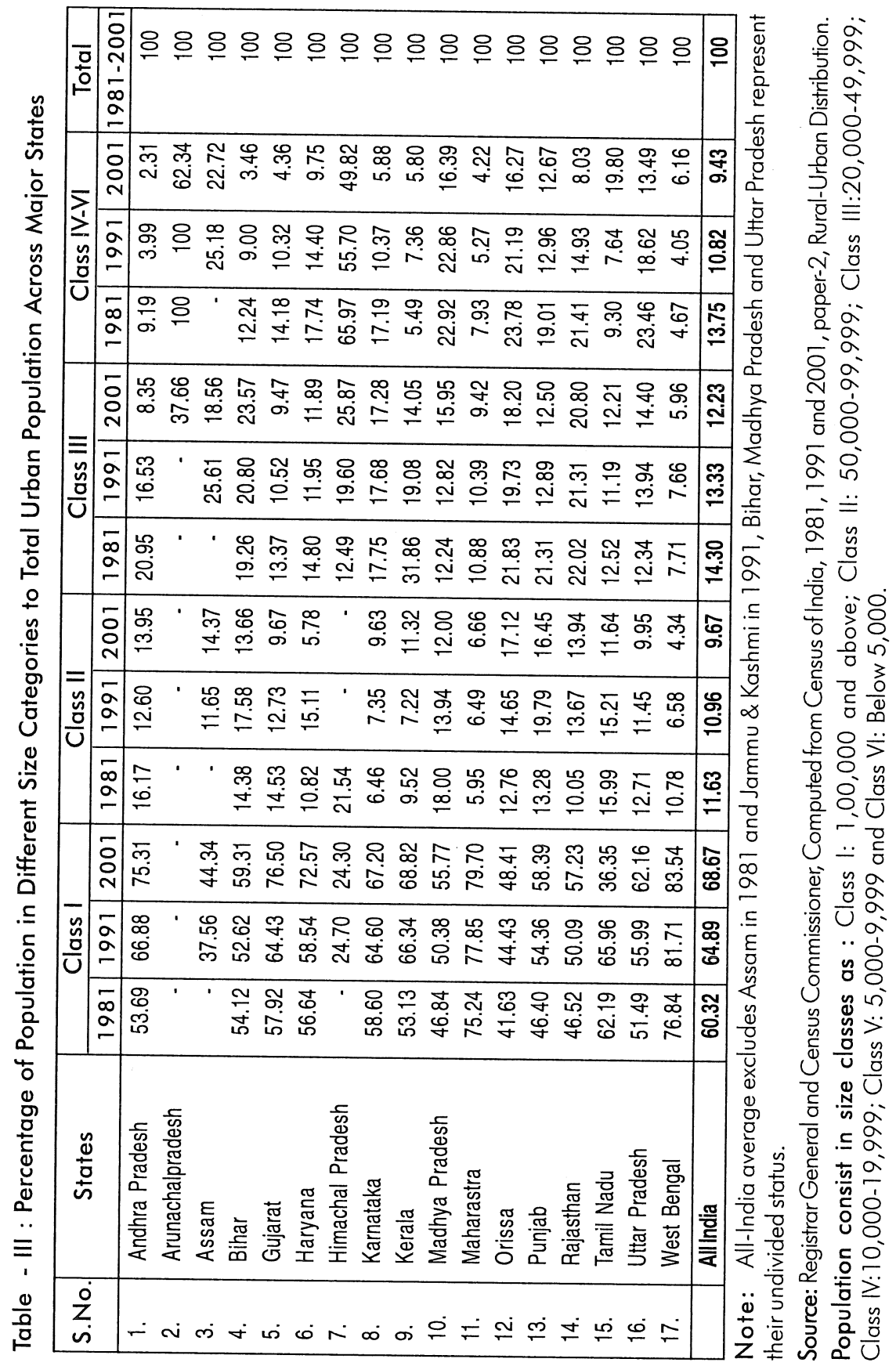


population concentrated in small size class towns (Class IV to VI) as well as medium size towns (Class II and III). While in case of Assam, the share of population by size classes is more or less equal, though slightly higher proportion recorded in class I cities. These states are far behind in development. Further, agriculture is mainstay of the economy and the opportunity for big and heavy industry in these states are limited because of topographical and other factors, there by less influence of migration which leads to low pattern of urbanization in large size classes.

\section{Summary}

Economic development has been regarded a significant factor an increasing urbanization, which is confirmed from the analysis of the trends as well as pattern of the urban scenario among major states. The developed states like Maharastra, Tamil Nadu, Gujarat, Karnataka, Punjab and West Bengal had a higher proportion of urbanization and stands above the national average. While, less developed states like Bihar, Orissa, and hilly states like Assam, Arunachal Pradesh and Himachal Pradesh recorded low pattern of urbanization. The trends in growth of urban population characterized by dualism. Backward states had high growth rate as a result of migration and by a gap-filling approach. While, few developed states had a high or moderate growth rate due to economic development there in industrialization and agrarian based sector have developed resulting to rural-urban migration.

An overwhelming proportion of urban population inhabited in class I cities of West Bengal, Maharastra, Tamil Nadu, Gujarat and Andhra Pradesh. Further, in some states also a moderate share of population concentrated in class I cities, as is the case of national average. The high pattern of urbanization in class I cities signals the enormity of the urban problems such as socio-economic, environmental and administrative aspects etc. In contrast, the hilly states like Arunachal Pradesh and Himachal Pradesh, however, an over whelming proportion of urban population concentrated in small size classes (IV to VI class town) and medium size classes (II and III class towns). While in Assam, the concentration of urban population is more or less equal among the all urban size classes though slightly higher proportion recorded in class I cities. Thus, the urbanization scenario in India is diverse in nature by higher levels and pattern recorded in socio-economically developed states and mostly characterized by class I cities oriented urbanization in major states, causes for regional imbalances. There is a need to develop the backward states as well. 


\section{Suggestions}

(1) Incentives for industrialization have to be adopted in backward states where in low pattern of urbanization existed.

(2) Medium and small class of towns should be developed with infrastructural, economic activities and linked with rural hinterland.

(3) Agro based as well as small scale industries has to be developed in rural areas which curtail migration.

(4) Development of roads and transport services linking with rural sector stimulus to commutation rather than migration.

(5) Improvement in employment as well as infrastructural facilities in rural areas holds population than push the population.

\section{References}

1) Ashish Bose; 1978: India's Urbanization, 1901-2001; New Delhi: Tata McGraw-Hill Publishing Company Limited, pp.3-545.

2) Bhande, A. and Kanitkar, T; 2006: Principles of Population Studies, Mumbai: Himalaya Publishing House, pp.410-426.

3) Jacob, Z.T; 2007: Urban Community Development, New Delhi: Rawat Publications, pp.9183.

4) Oberai, A.S; 1993: Population Growth, Employment and Poverty in Third World Mega cities, Proceedings of International Conference, Montreal, Vol.2, pp.105-149.

5) Patil, R.L; 1993: The Process of Urbanization in India, 1971-1991; Mumbai: The Journal of Family Welfare, Vol.39, No.1, pp.44-51.

6) Premi, M.K; 2003: Social Demography: A systematic exposition, New Delhi: Jawahar Publishers \& Distributors, pp.75-157.

7) Sankar Rao, C.K; 2007: Sociology: Principles of Sociology with an Introduction to Social Thought; New Delhi: S. Chand \& Company Ltd; pp.3-854.

8) Singh; 1992: Urbanisation, Poverty and Employment: The large metropolis in the third world contribution to political economy. Vol.II, pp.25-40.

9) Sivaramakrishnan, K.C. et al;, 2006: Hand Book of Urbanisation in India: An Analysis of Trends and Processes; New Delhi: Oxford University Press, pp.2-135. 